\title{
Brain MRI features in late-onset nonketotic hyperglycinemia
}

\author{
Achados de RM de crânio na hiperglicinemia não-cetótica de início tardio \\ Wladimir Bocca Vieira de Rezende Pinto, Paulo Victor Sgobbi de Souza, Adrialdo José Santos
}

A 22-year-old woman presented with learning disability and gait unsteadiness since adolescence. Medical history revealed episodes of encephalopathy and myoclonic jerks associated with intercurrent infections. Examination showed spastic paraparesis, ataxia and optic atrophy. Neuroimaging revealed agenesis of corpus callosum (Figure). Plasma amino acid analysis disclosed elevated glycine levels with an increased cerebrospinal fluid:plasma glycine ratio.
Nonketotic hyperglycinemia (MIM \#605899) is an autosomal recessive disorder of glycine metabolism caused by a defect in the glycine cleavage system with three different clinical forms: neonatal, infantile and late-onset with heterogeneous brain malformations, such as abnormal corpus callosum, gyral malformations and enlarged ventricles ${ }^{1,2}$.
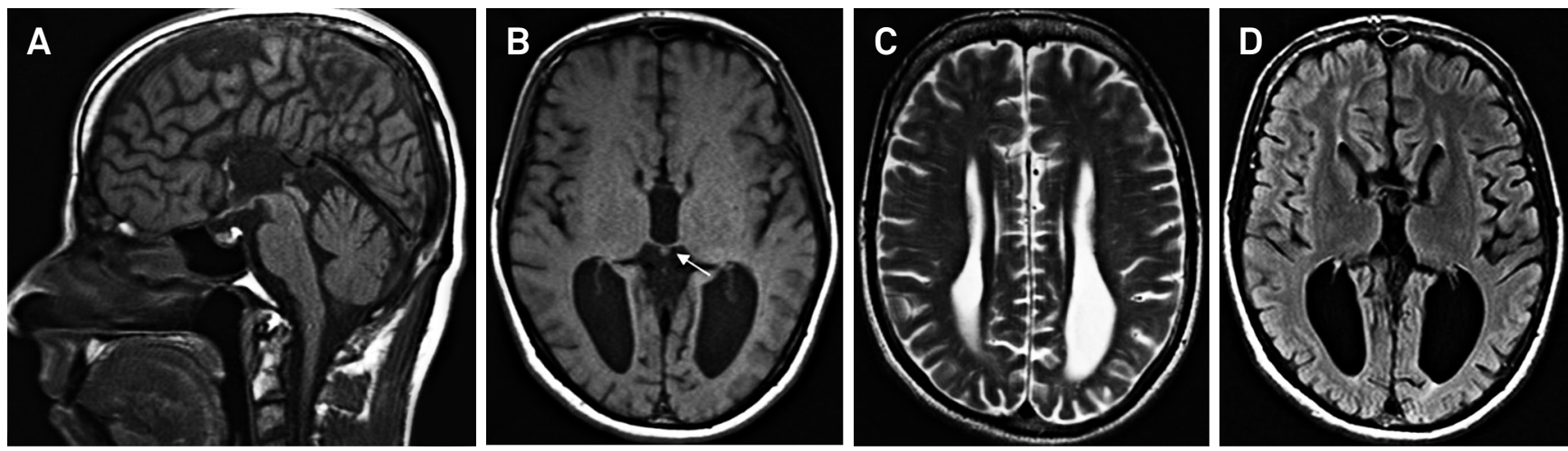

Figure. Neuroimaging findings in nonketotic hyperglycinemia. Sagittal and axial brain MR images disclosing nearly complete corpus callosum agenesis (sparing only a small portion of the genu) and interhemispheric connection by posterior commissure (white arrow) in T1-weighted (A, B), T2-weighted (C) and FLAIR (D) sequences. Putamina, anterior commissure and hemispheric supratentorial white matter are also thin.

1. Hoover-Fong JE, Shah S, Van Hove JLK, Applegarth D, Toone J, Hamosh A. Natural history of nonketotic hyperglycinemia in 65 patients. Neurology. 2004;63(10):1847-53. doi:10.1212/01.WNL.0000144270.83080.29
2. Dobyns WB. Agenesis of the corpus callosum and gyral malformations are frequent manifestations of nonketotic hyperglycinemia. Neurology. 1989;39(6):817-20. doi:10.1212/WNL.39.6.817

Universidade Federal de São Paulo, Departamento de Neurologia e Neurocirurgia, Sao Paulo SP, Brazil.

Correspondence: Wladimir Bocca Vieira de Rezende Pinto; UNIFESP, Departamento de Neurologia e Neurocirurgia; Rua Pedro de Toledo, 650; $04023-900$ São Paulo SP, Brasil; E-mail:wladimirbvrpinto@gmail.com

Conflict of interes: There is no conflict of interest to declare.

Authors disclosures: Dr. Pinto (WBVR) reports no disclosures. Dr. Souza (PVS) reports no disclosures. Dr. Santos (AJ) reports no disclosures. Ethical statement: Full consent was obtained from the patient's family for the case report. This study was approved by our Ethics Institution. Received 30 March 2015; Received in final form 09 June 2015; Accepted 29 June 2015. 